\title{
Optimization of anaerobic digestion of sludge to produce volatile fatty acids
}

\author{
A. F. A. Rahim, S. R. M. Kutty \& A. Malakahmad \\ Department of Civil Engineering, \\ Universiti Teknologi PETRONAS, Malaysia
}

\begin{abstract}
Sludge is a waste formed during treatment of wastewater. In Malaysia, Indah Water Consortium (IWK) has been responsible for providing sewerage services, operating and maintaining over 5,834 public sewage treatment plants and $15,645 \mathrm{~km}$ networks of sewerage pipelines since April 1994. IWK generates 3.2 million cubic meters of domestic sludge yearly and the amount is expected to increase due to the increment of population and urbanization. Due to the unpredicted price of diesel in the world market, the world is searching for alternative, cheap and renewable energy resources that promise no environmental impact like biodiesel, bioethanol and biogas derived from renewable biomass. Sludge digestions produce volatile fatty acid (VFAs) which are essential in the production of biodiesel. Therefore, optimization of the anaerobic sludge digestion is needed to fulfil the demand. The objective of this study is to optimize the anaerobic sludge digestion for the production of volatile fatty acids. The digestion of sludge was carried out using an anaerobic sludge digester. The production of the volatile fatty acids was optimized by varying the cycle period of the digestion process and maintaining the concentration of MLSS to $8000 \mathrm{mg} / \mathrm{L}$ for each cycle. The highest production of volatile fatty acids was obtained using five days of cycle period which is $441 \mathrm{mg} / \mathrm{L}$ as acetic acid (HOAC).
\end{abstract}

Keywords: volatile fatty acids, anaerobic digestion, sludge.

\section{Introduction}

Anaerobic digestion is one of the processes used for the sewage treatment. It has been conducted in many countries in the world where it began in 1859 with the 
first digestion plant in Bombay. Due to industrialization, understanding of the anaerobic digestion and its benefits, operational techniques and more sophisticated equipment emerged. In order to optimize anaerobic digestion, closed tank, heating and mixing was used. Anaerobic digestion has been and continues to be widely used processes for the stabilization of wastewater treatment plant sludge. Generally, anaerobic digestion is a biological process that can degrade waste organic material by concerted action of a wide range of microorganisms in the absence of oxygen. Before final disposal, anaerobic digestion is an appropriate technique for the treatment of waste activated sludge and it is employed worldwide [1]. However, approximately $20 \%-30 \%$ of the sludge Total Solid (TS) is mineralized using nowadays technologies [2]. At lower costs and the high destruction rate of pathogens, the stabilization of large volumes of organic sludge is obtained [3]. Due to the unpredicted price of the fuel diesel in the world market, world is searching for alternative, cheap and renewable energy resources that promises no environmentally impact like biodiesel, bioethanol and biogas derived from renewable biomass. Anaerobic digestion of sludge can produce volatile fatty acids which is essential for the production of biodiesel. For this study, the sample of sludge was taken from wastewater treatment plant at Universiti Teknologi PETRONAS (UTP). The sludge was collected in a secondary clarifier that promises a high amount of MLSS.

\section{Methodology}

\subsection{Digestion of primary sludge}

Two liters of primary sludge were digested in a $2 \mathrm{~L}$ reactor (anaerobic sludge digester) for 6 different batches with varying digestion cycle periods $(1,2,3,4$ and 5 days); at two different temperatures; mesophilic $\left(35^{\circ} \mathrm{C}\right)$ and thermophilic $\left(55^{\circ} \mathrm{C}\right)$. In order to maintain the biomass constant for each reactor, the MLSS of the sludge was determined and each reactor received only $8000 \mathrm{mg} / \mathrm{L}$ concentration of biomass. The sludge was mechanically mixed at a constant speed of $125 \mathrm{rpm}$ by reactor stirrers. Anaerobic conditions were assured by keeping the digester reactor sealed. When the cycle period finished, $200 \mathrm{~mL}$ of sludge were sampled and analyzed for VFAs, mixed liquor suspended solids (MLSS), mixed liquor volatile suspended solids (MLVSS), pH, ammonia nitrogen, nitrate, and alkalinity. At the end of each cycle period, the digested product obtained from the reactor was centrifuged for $15 \mathrm{~min}$ at $8000 \mathrm{rpm}$, and the supernatant was used for the tests mentioned.

\subsection{Analytical method}

The samples were centrifuged at $8800 \mathrm{rpm}$ for $15 \mathrm{~min}$ and the supernatant was filtered through a $47 \mathrm{~mm}$ filter paper disc prior to analyses. MLSS and MLVSS test was performed according to Standard Methods 2540-D. Alkalinity test was performed according to Standard Methods 2320. For ammonia-nitrogen and 
nitrate test, the test was performed according to Nessler methods and Cadmium Reduction methods respectively. All the analyses were performed in triplicates and using a dilution factor of 1:250 except for alkalinity test (using non-diluted supernatant). For VFAs determination, $0.5 \mathrm{ml}$ of the filtrate supernatant was placed in $25 \mathrm{ml}$ sample cells. The sample was tested according to Esterification method (Method 8196) using spectrophotometer. The results of the VFAs were $\mathrm{read}$ in $\mathrm{mg} / \mathrm{L}$ HOAC.

\section{Result and discussions}

\subsection{MLSS concentration}

The result indicated that the initial MLSS concentration of $8000 \mathrm{mg} / \mathrm{L}$ decreased to $5200 \mathrm{mg} / \mathrm{L}$ and $6433 \mathrm{mg} / \mathrm{L}$ (see Figure 1), for mesophilic and thermophilic conditions, respectively. This may be due to the acclimatization of the biomass to the new environment. However, it can be observed from Figure 1 that as the digestion period was increased, the MLSS concentration increased gradually for both temperature conditions. The increase of MLSS concentration in the thermophilic phase was found to be slightly higher than the mesophilic phase.

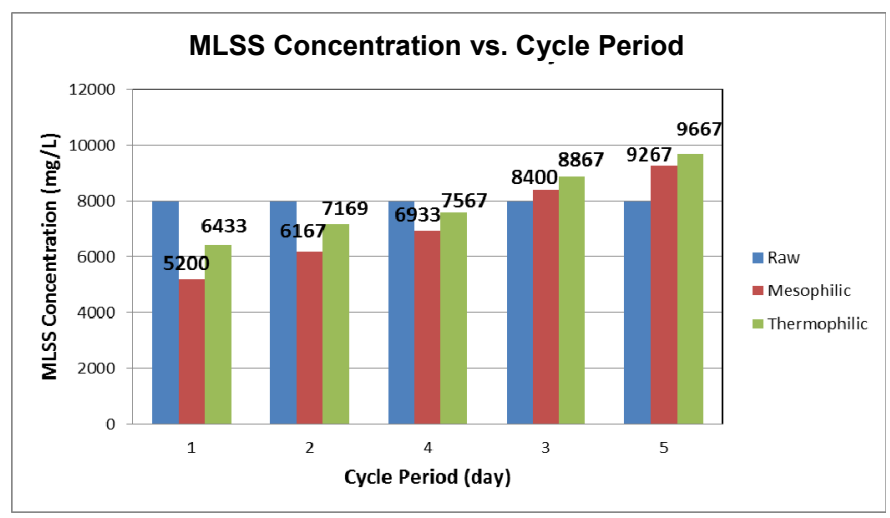

Figure 1: Graph of MLSS concentration vs. cycle period.

\subsection{MLVSS concentration}

The TSS and VSS concentration in the primary sludge composition were important parameters that influenced the production of VFAs. In order to predict VFAs production, sufficient TSS and VSS must be present [4] with high solids content promoting higher VFAs production [5]. From the result shown in Figure 2, the growth of MLVSS was found to be similar as MLSS in Figure 1. When the digestion period was less than 4 days, it can be observed that initial MLVSS decreased at the end of each cycle period. At a digestion period of 5 days, highest production of MLVSS was achieved which promises the production of VFAs. 


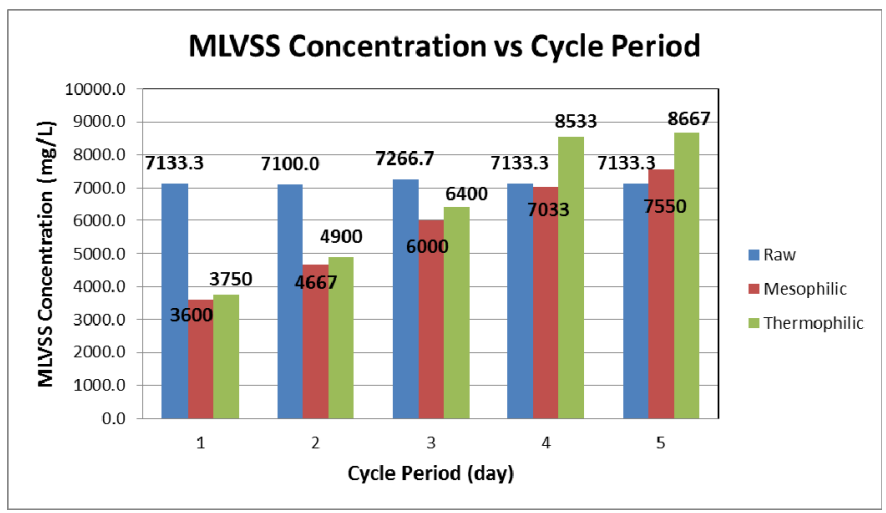

Figure 2: Graph of MLVSS concentration vs. cycle period.

\subsection{Ammonia-nitrogen concentration}

In UTP sewage treatment plant, the wastewater was treated aerobically using an extended activated sludge system. Therefore, nitrification takes place in the aeration tank. The filtrate of the raw sludge showed low ammonia-nitrogen concentration which resulted from nitrification in the aeration tank. The initial increase in ammonia-nitrogen concentration in both thermal conditions suggests that it is due to the endogenous decay of the biomass due to some presence of oxygen as well as through hydrolysis of the organic matter in the initial stages of anaerobic digestion. The ammonia-nitrogen concentration for both thermal conditions increased with higher digestion cycle period as shown in Figure 3. However, it can be observed that the ammonia-nitrogen concentration in the thermophilic and mesophilic phase peaked at day 3 and day 4, respectively. This indicates that degradation/hydrolysis of organic into ammonia is slower at lower temperature (mesophilic phase).

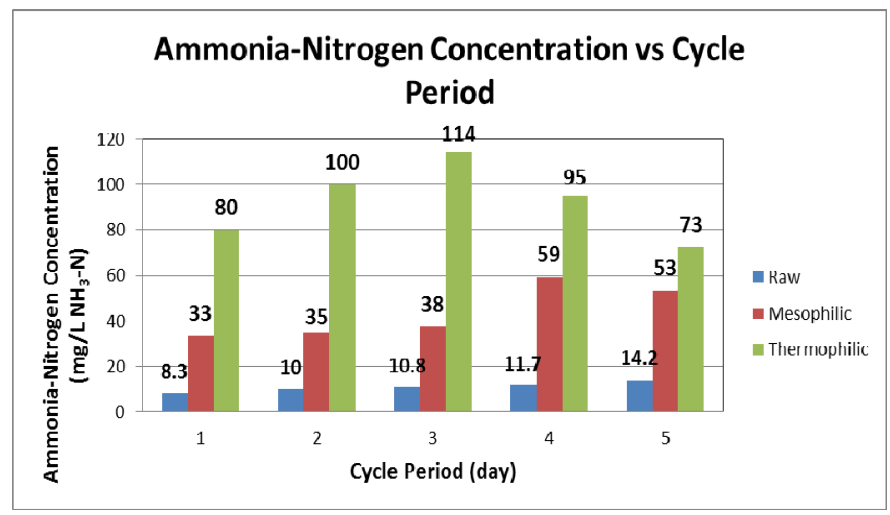

Figure 3: Graph of ammonia-nitrogen vs. cycle period. 


\subsection{Nitrate concentration}

The nitrate concentration vs. cycle period is also presented in Figure 4. The initial increase in nitrate concentration in both thermal conditions suggests that it is due to the nitrification of ammonia produced from the endogenous decay as well as hydrolysis of the organic matter. However, it can be observed that the nitrate concentration in the thermophilic and mesophilic phase peaked at day 3 and day 4, respectively. This indicates that nitrification is slower at lower temperature (mesophilic phase). Similar trend was observed for the ammonianitrogen concentration. The concentration of nitrate dropped after reaching the peak at higher digestion cycle period for both ammonia-nitrogen and nitrate concentrations.

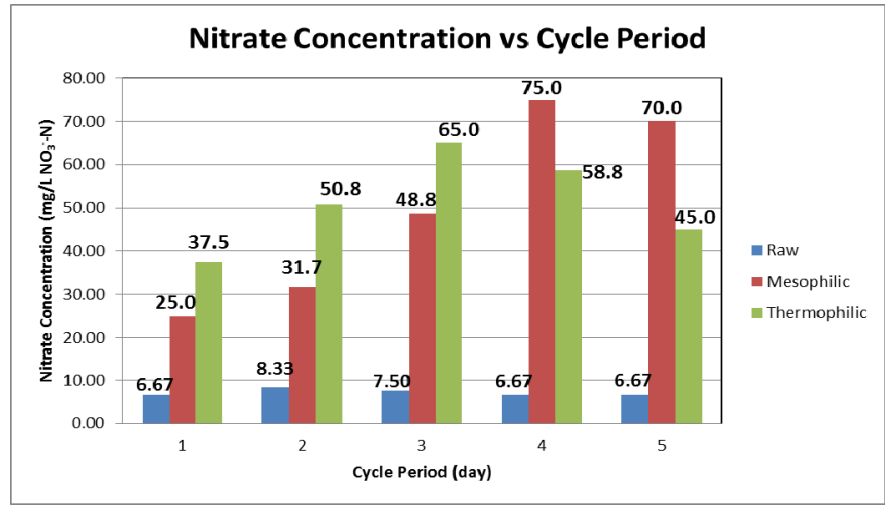

Figure 4: Graph of nitrate concentration vs. cycle period.

\subsection{Alkalinity}

In Figure 5, it can be observed that the raw alkalinity was used up during nitrification for the mesophilic and thermophilic phase, up to 3 days and 4 days

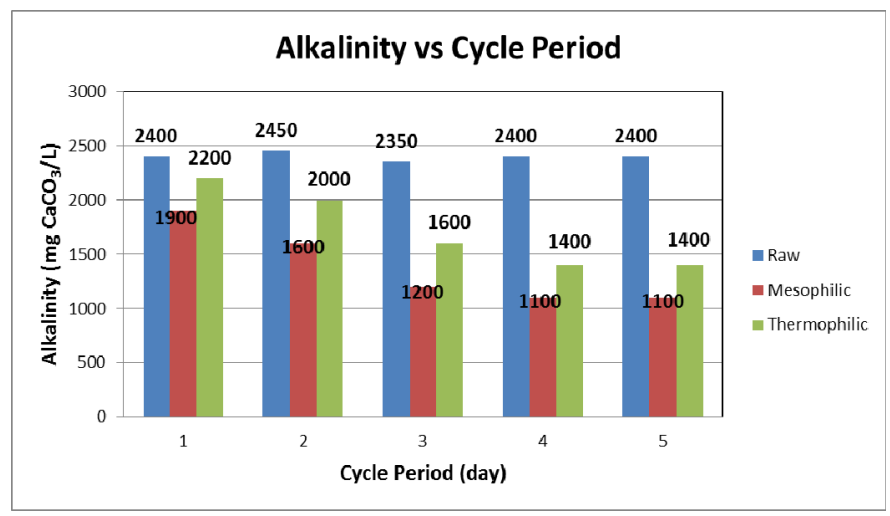

Figure 5: Graph of alkalinity vs. cycle period. 
cycle period, respectively. The alkalinity stabilized to $1100 \mathrm{mg} / \mathrm{L}$ as $\mathrm{CaCO}_{3}$ and $1400 \mathrm{mg} / \mathrm{L}$ as $\mathrm{CaCO}_{3}$, for the mesophilic and thermophilic phases, respectively.

\section{$3.6 \mathrm{pH}$}

Figure 6 shows the $\mathrm{pH}$ during the sludge digestion for day one to day five of digestion. Initial $\mathrm{pH}$ of sludge was approximately $\mathrm{pH}$ 7. It can be observed that for the thermophilic digestion, the final $\mathrm{pH}$ reduced as the digestion cycle period was increased from 3 to 5 days. This is due to the production of VFAs from 3 to 5 days for the thermophilic phase as shown in Figure 7. It can be observed that $\mathrm{pH}$ for the mesophilic digestion remained steady for all cycle periods and less VFAs were produced.

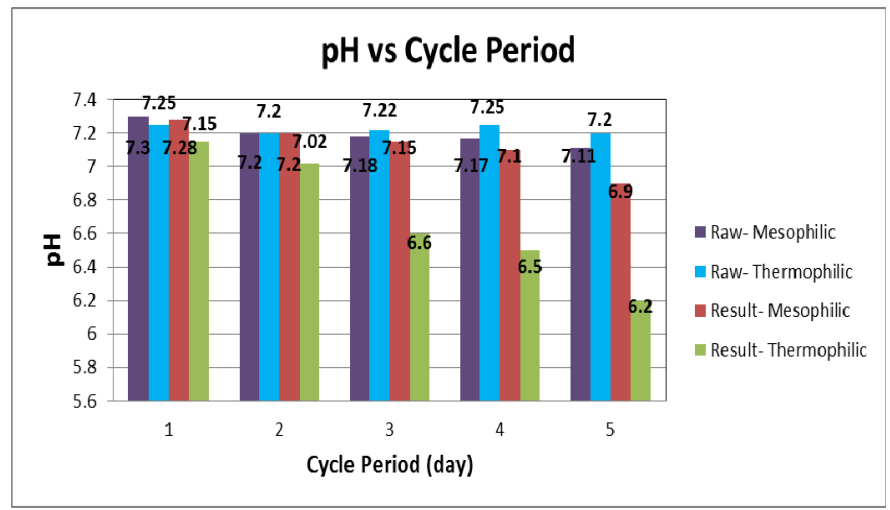

Figure 6: Graph of $\mathrm{pH}$ vs. cycle period.

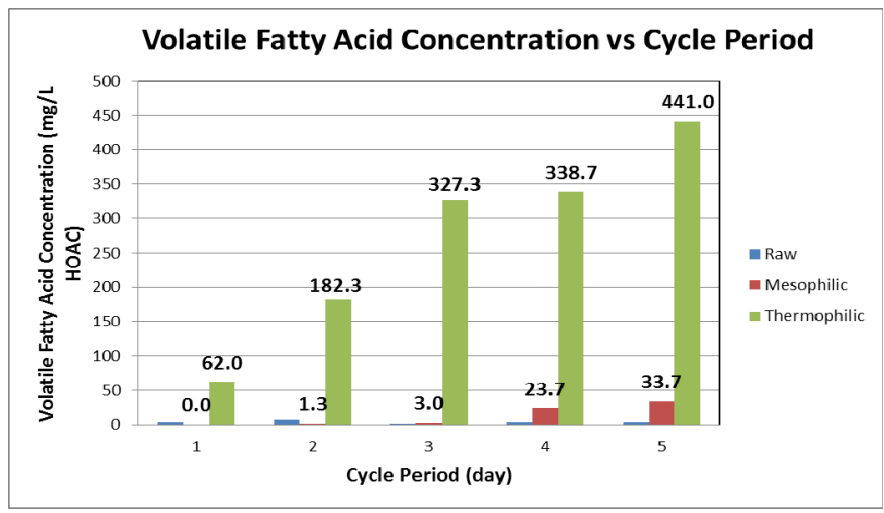

Figure 7: Graph of volatile fatty acids vs. cycle period. 


\subsection{Volatile fatty acids (VFAs)}

In Figure 7, it can also be observed that for mesophilic digestion, the production of VFAs was much slower compared to the thermophilic digestion whereby VFAs rapidly increased starting for reactors operating at day 1 to day 5 digestion periods. The thermophilic digestion operating for 5 days achieved the highest production of VFAs compared to the mesophilic digestion.

\section{Conclusions}

As conclusion, the production of VFAs can be achieved through anaerobic digestion of municipal sludge. With an initial MLSS of $8000 \mathrm{mg} / \mathrm{L}$ at the beginning of the digestion for each cycle period, the highest production of VFAs was achieved after five days of digestion with $441 \mathrm{mg} / \mathrm{L} \mathrm{HOAC}$.

\section{Acknowledgements}

Financial support was provided by Exploratory Research Grant Scheme (ERGS) by the Ministry of Higher Education of Malaysia. The authors would also like to thank the Environmental Laboratory staff, Civil Engineering Department of Universiti Teknologi PETRONAS for their support in this research.

\section{References}

[1] M. Dohanyos, J. Zabranska. (2001). Sludge into biosolids: processing, disposal and utilization. IWA, 13: 223-241.

[2] W. Rulkens. (2008). Sewage sludge as a biomass resource for the production of energy: overview and assessment of the various options. Energy Fuel, 22: 9-15.

[3] T. Liu. (1998). Anaerobic digestion of solid substrates in an innovative Two-Phase Plug-Flow Reactor (TPPFR) and a conventional single-phase continuously stirred tank reactor. Water Sci. Technol., 38 (8-9), 453-461.

[4] S.S. Banister and W. Pretorius (1998). Optimisation of primary sludge acidogenic fermentation for biological nutrient removal. Water SA. 24(1): 35-41.

[5] Zeng R. J., Yuan Z. and Keller J. (2006). Effects of solids concentration, pH and carbon addition on the production rate and composition of volatile fatty acids in prefermenters using primary sewage sludge. 